CLINICAL STUDY

\title{
Genetic variation in exon 17 of INSR is associated with insulin resistance and hyperandrogenemia among lean Indian women with polycystic ovary syndrome
}

\author{
Srabani Mukherjee, Nuzhat Shaikh, Sushma Khavale, Gayatri Shinde, Pervin Meherji, Nalini Shah ${ }^{1}$ \\ and Anurupa Maitra \\ Department of Molecular Endocrinology, National Institute for Research in Reproductive Health, Indian Council of Medical Research (ICMR), Jehangir \\ Merwanji Street, Parel, Mumbai 400012, India, and ${ }^{1}$ Seth G S Medical College and KEM Hospital, Parel, Mumbai, 400012, India
}

(Correspondence should be addressed to S Mukherjee; Email: mukherjees@nirrh.res.in)

\begin{abstract}
Objective: Polycystic ovary syndrome (PCOS) is a multigenic disorder, and insulin resistance is one of its hallmark features. Polymorphisms in exon 17 of insulin receptor (INSR) gene are reported to be associated with PCOS. We investigated this association in Indian women and its putative relationship with PCOS associated traits, which has not been explored so far.

Methods: In this case control study, the polymorphisms were investigated by direct sequencing in 180 women with PCOS and 144 age matched controls. Clinical, anthropometric, biochemical, and hormonal parameters were also estimated.

Results: The silent C/T polymorphism at His1058 in exon 17 of INSR was found to be present in our study population. The polymorphic genotype $(\mathrm{CT}+\mathrm{TT})$ was significantly associated with PCOS in lean women $\left(\chi^{2}=8.493, \mathrm{df}=1, P=0.004\right)$. It showed association with higher fasting insulin levels $(P=0.02)$, homeostasis model assessment of insulin resistance $(P=0.005)$, free androgen index $(P=0.03)$, and lower quantitative insulin sensitivity check index $(P=0.004)$ in lean PCOS women. No other novel or known polymorphism was identified in exon 17 in this cohort.

Conclusions: The study shows significant association of $\mathrm{C} / \mathrm{T}$ polymorphism at His1058 of INSR with $\mathrm{PCOS}$ in the lean rather than obese Indian women. Its association with indices of insulin resistance and hyperandrogenemia is also seen in the same group. The findings strengthen the concept that pathogenesis of PCOS is different in lean and obese women.
\end{abstract}

European Journal of Endocrinology 160 855-862

\section{Introduction}

Polycystic ovary syndrome (PCOS) is a heterogeneous disorder with a prevalence of $\sim 7 \%$ in women of childbearing age (1). It is the most common cause of anovulatory infertility with characteristic manifestations such as menstrual irregularities; signs of androgen excess like hirsutism, acne, alopecia; altered LH:FSH ratio $(>2: 1)$ and polycystic ovaries $(2-4)$. The majority of women with PCOS have insulin resistance, which plays a key role in its pathogenesis $(5,6)$. In addition, it increases the risk of developing glucose intolerance, type 2 diabetes mellitus, hypertension, and dyslipidaemia, which can lead to cardiovascular disorders in later life (7-10). Both obese and lean women with PCOS manifest insulin resistance (2) and obesity further contributes an additional component of insulin resistance (5). Insulin resistance progresses towards compensatory hyperinsulinemia, which promotes both hyperandrogenemia and anovulation in $\operatorname{PCOS}(1,11)$.
Familial clustering seen in this syndrome suggests contribution of a genetic component to its pathogenesis $(12,13)$. Over the past decade, a number of candidate genes involved in steroidogenesis, insulin signaling pathway, gonadotropin secretion and chronic inflammation have been explored to identify the susceptibility genes for PCOS $(14,15)$; however, the results so far have been inconclusive.

Available evidence suggests insulin resistance in PCOS could be due to post-binding defects in insulin signaling $(2,16,17)$. Hence, insulin receptor (INSR), being an integral part of insulin signaling could be a potential candidate gene. INSR is located on chromosome 19 and encompasses 22 exons. Linkage analysis studies that have found an association of the microsatellite marker D19S884 which is located on chromosome $19 \mathrm{p} 13.2$ and relatively close $(1 \mathrm{cM})$ to INSR with PCOS, emphasize it to be a candidate gene $(18,19)$. Other studies showed that the number and affinity of insulin receptor is not altered in PCOS but its tyrosine phosphorylation status and subsequent signaling is 
affected, suggesting the defect may lie in the $\beta$-chain $(16,20)$. Studies to determine mutations in INSR failed to find any major variations; however, several polymorphisms were identified (21-28). The most frequent of these were at exon 17, which encodes the partial tyrosine kinase domain containing the ATP binding site of INSR, important for its downstream signaling (21-28). Among these polymorphisms, a C/T SNP at His 1058 in exon 17 has been reported to be significantly associated with PCOS in two independent studies in Caucasian and Chinese women (25, 26). A subsequent study from Korea however, failed to confirm this association (27). Also, the possible relationship between this polymorphism and PCOS associated traits has not been explored so far. In another study, a novel T/C polymorphism at Cys 1008 in exon 17 of INSR was found to be associated with PCOS and insulin resistance, which is yet to be verified independently (28). Nevertheless, these studies do suggest that the genetic variants in exon 17 of INSR may have an association with PCOS or its pathophysiology. Thus, in the present study, we sought to evaluate the association of genetic variations in exon 17 of INSR with PCOS and its related traits in Indian women, who are ethnically distinct from the populations already studied.

\section{Subjects and methods}

\section{Subjects}

A total of 180 Indian women with PCOS, aged 17-39 years were recruited consecutively from the Infertility Clinic of the National Institute for Research in Reproductive Health (NIRRH) as well as the Endocrinology Clinic of Seth GS Medical College and KEM Hospital, Mumbai, India. The diagnosis of PCOS was defined by ESHRE/ASRM consensus criteria, including presence of at least two of the following three features: i) oligomenorrhoea and/or anovulation, ii) clinical and/or biochemical signs of hyperandrogenemia, and iii) polycystic ovaries on ultrasound (29). Other related disorders like non-classical congenital adrenal hyperplasia, thyroid dysfunction, androgen secreting tumors, and hyperprolactinemia were excluded. One hundred and fifty healthy Indian women, aged 17-38 years, with regular menstrual cycles and no clinical and/or biochemical signs of hyperandrogenemia or polycystic ovaries were carefully selected for the study as the control group from the general population. On detailed biochemical evaluation, six control women were excluded mainly due to abnormal thyroid status. The women in the control and PCOS groups were genetically unrelated. Women with diabetes were excluded from the study. None of the subjects had taken any medication known to affect carbohydrate and lipid metabolism or endocrine parameters for at least 3 months prior to entering the study. Ethical committee approval from both institutions and written informed consent from all participants were obtained.

\section{Clinical and laboratory parameters}

The anthropometric data - height, weight, body mass index (BMI), waist, and hip circumference, waist to hip ratio were obtained from all subjects. Blood samples were collected between 3-7 days of the menstrual cycle (early follicular phase) or during amenorrhea and serum was stored at $-80{ }^{\circ} \mathrm{C}$ until assayed. After overnight fasting, each subject underwent an oral glucose tolerance test. Glucose and insulin levels were measured at $0 \mathrm{~min}$ and $2 \mathrm{~h}$ after $75 \mathrm{~g}$ glucose load. Fasting serum were used to measure total testosterone, androstenedione, sex hormone binding globulin (SHBG), LH, FSH, TSH, T3, T4, and prolactin levels. Glucose was measured enzymatically by glucose oxidase method. TSH, T3, T4, FSH, LH, and prolactin were measured by chemiluminescence immunoassay (Immulite 1000, Llanberis, UK). Serum insulin, total testosterone, androstenedione, and SHBG levels were measured using commercial kits (DSL-1600 RIA kit, DSL-4000 RIA kit, DSL-3800 RIA kit and DSL-7400 IRMA kit respectively from Diagnostic System Laboratories, Webster, TX, USA). Free testosterone (active free testosterone in circulation) and bioavailable testosterone (free plus weakly bound to albumin) was calculated from total testosterone and SHBG values using a web-based calculator (http://www.issam.ch/ freetesto.htm) (30). Free-androgen index (FAI) was assessed by the following formula: total testosterone $(\mathrm{nmol} / \mathrm{l}) / \mathrm{SHBG}(\mathrm{nmol} / \mathrm{l}) \times 100(31)$. Insulin resistance was evaluated by the homeostasis model assessment of insulin resistance (HOMA-IR) using the following formula: fasting plasma glucose $(\mathrm{mmol} / \mathrm{l}) \times$ fasting insulin $(\mu \mathrm{U} / \mathrm{ml}) / 22.5)$ (32). Insulin sensitivity was assessed by quantitative insulin sensitivity check index (QUICKI), defined as $1 /(\log$ fasting serum insulin $(\mu \mathrm{U} / \mathrm{ml})+\log$ fasting plasma glucose $(\mathrm{mg} / \mathrm{dl}))(33)$. Obesity was defined as BMI $\geq 23 \mathrm{~kg} / \mathrm{m}^{2}$ based on Indian norms (34), accordingly, subjects were categorized as lean $\left(\right.$ BMI $\left.<23 \mathrm{~kg} / \mathrm{m}^{2}\right)$ and obese $\left(\right.$ BMI $\left.\geq 23 \mathrm{~kg} / \mathrm{m}^{2}\right)$.

\section{Genetic analysis}

Genomic DNA was extracted from peripheral whole blood by QIAamp DNA Blood Mini Kit (Qiagen $\mathrm{GmbH}$ ). Exon 17 was amplified using the following primers: 5'-CCAAGGATGCTGTGTAGATAAG-3' and 5'-TCAGGAAAGCCAGCCCATGTC-3' according to Siegel et al. with some modifications (25). The amplifications were performed using $0.5 \mu \mathrm{g}$ genomic DNA in a final volume of $50 \mu \mathrm{l}$ containing $1.5 \mathrm{mM} \mathrm{MgCl}_{2}, 200 \mathrm{mM}$ of each dNTPs, 10 pmol of each primer and $0.5 \mathrm{U}$ of Taq Polymerase (Fermentas, Vilnius, Lithuania). After initial denaturation for $5 \mathrm{~min}$ at $94^{\circ} \mathrm{C}, 35$ cycles of amplifications were carried out at $94{ }^{\circ} \mathrm{C}$ for $45 \mathrm{~s}, 56{ }^{\circ} \mathrm{C}$ for $40 \mathrm{~s}$, 
and at $72{ }^{\circ} \mathrm{C}$ for $1 \mathrm{~min}$ with a final extension of $10 \mathrm{~min}$ at $72{ }^{\circ} \mathrm{C}$. The resulting amplified product was of $317 \mathrm{bp}$, which was purified by QIAquick Gel Extraction Kit, (Qiagen $\mathrm{GmbH}$ ) and subjected to direct sequencing in 3130xl Genetic Analyzer using Big Dye Terminator Chemistry (Applied Biosystems, Foster City, USA).

\section{Statistical analysis}

Univariate comparison of all continuous variables between the PCOS and control groups were done by unpaired $t$-tests. Results are expressed as mean \pm s.D. The association between genotype and PCOS was analyzed using $\chi^{2}$ test. Stratified analysis by obesity (i.e., lean BMI $<23 \mathrm{~kg} / \mathrm{m}^{2}$ and obese BMI $\geq 23 \mathrm{~kg} / \mathrm{m}^{2}$ ) was also performed. Variables that were significant at the univariate level were further assessed in multivariable analysis. Analysis of covariance (ANCOVA) was used to compare hormonal profiles between genotypes after adjusting for age and BMI. Statistical significance was based on a $P<0.05$. Statistical analysis was performed by using SAS version 9.2 software packages.

\section{Results}

The clinical, anthropometric, and hormonal parameters of control and PCOS women per se and as per obesity status have been depicted in Table 1 . The majority of the women with PCOS were oligomenorrhoeic (55\%, 99/180), whereas 38.9\% (70/180) were amenorrhoeic and the rest $6.1 \%(11 / 180)$ were regularly cycling. As regards clinical signs of hyperandrogenism, 53.3\% $(96 / 180)$ of PCOS women presented with hirsutism, $36.1 \%(65 / 180)$ with acne and 16\% (29/180) with mild alopecia.

The control and PCOS women were of similar mean age but did differ significantly with respect to anthropometric parameters $(P<0.05)$ (Table 1$)$. The PCOS women had significantly higher levels of fasting and $2 \mathrm{~h}$ glucose and fasting insulin compared with controls, although within normal range. Insulin resistance index like HOMA-IR $(P<0.0001)$ was elevated and insulin sensitivity as measured by QUICKI (vs $P<0.0001$ ) was low in PCOS women (Table 1 ). Even after classifying control and PCOS women in lean and obese groups, the BMI, $2 \mathrm{~h}$ glucose level, fasting insulin level, and HOMA-IR remained higher, whereas QUICKI was lower in both PCOS groups compared with controls. Acanthosis nigricans, a sign of insulin resistance, was present in $23.3 \%$ of PCOS women (42/180).

Women with PCOS were more hyperandrogenic exhibiting higher levels of total, free, and bioavailable testosterone, androstenedione, and increased FAI values $(P<0.0001)$. The difference between these hormones was more evident in the obese rather than in the lean group (Table 1). SHBG levels were significantly lower in obese PCOS women $(P<0.0001)$, which is common in obesity and insulin resistance state (35), with concurrent high free and bioavailable testosterone $(P<0.0001)$ and FAI $(P<0.0001)$.

Analysis of exon 17 of INSR by direct sequencing revealed presence of one silent polymorphism, a $\mathrm{C} / \mathrm{T}$ SNP at His 1058 site. No other known or novel polymorphism in this region was detected in this cohort. The genotype distributions of this SNP were in Hardy-Weinberg equilibrium. In our study cohort, $52.8 \%(76 / 144)$ of controls and $43.9 \%$ (79/180) of PCOS were CC; $38.9 \%$ (56/144) of controls and $42.8 \%$ (77/180) of PCOS were CT and 8.3\% (12/144) controls and $13.3 \%(24 / 180)$ PCOS women were TT. The frequencies of CT and TT genotypes were relatively high but not significantly different in PCOS women compared with controls $\left(\chi^{2}=3.416, \mathrm{df}=2, P=0.181\right)$.

PCOS women are frequently obese which also contributes to insulin resistance. To understand the relationship of this INSR polymorphism with obesity, the distribution of these genotypes in lean and obese groups were evaluated. The frequency of $\mathrm{CT}+\mathrm{TT}$ genotype was significantly higher in lean PCOS group $(69.3 \%, 52 / 75)$ compared with lean control group $(46.4 \%, \quad 39 / 84) \quad\left(\chi^{2}=8.493, \quad \mathrm{df}=1, \quad P=0.004\right)$ (Table 1). As the number of subjects with TT genotype was low in some subgroups, CT and TT genotypes were combined together as $\mathrm{CT}+\mathrm{TT}$ genotype.

To understand the influence of this polymorphism on PCOS related traits, indices of insulin resistance and hyperandrogenemia in both lean and obese groups of PCOS and controls were analyzed (Tables 2 and 3). The carriers of CC genotype did not differ significantly from polymorphic $(\mathrm{CT}+\mathrm{TT})$ genotype in lean control, obese control, and also in obese PCOS group, in terms of waist circumference, BMI, fasting glucose levels, fasting insulin levels and insulin resistance indices (HOMA-IR and QUICKI). Additionally, total testosterone levels, free and bioavailable testosterone, androstenedione, and FAI were also similar within these groups. Interestingly, the lean PCOS subgroup, with polymorphic genotype showed a significantly higher BMI $(20.48 \pm 1.77$ vs $\left.19.15 \pm 2.07 \mathrm{~kg} / \mathrm{m}^{2}, P=0.005\right)$ and waist circumference $(73.24 \pm 6.43$ vs $69.89 \pm 5.64 \mathrm{~cm}, P=0.03)$ compared with CC genotype. Furthermore, the indices of insulin resistance were significantly different between women with polymorphic and wildtype genotypes in the same group, showing higher fasting insulin levels $(11.43 \pm 5.22$ vs $8.32 \pm 2.70 \mathrm{uIU} / \mathrm{ml}, P=0.009)$ and HOMA-IR $(2.40 \pm 1.10$ vs $1.64 \pm 0.54, P=0.002)$ and lower QUICKI values $(0.340 \pm 0.021$ vs $0.357 \pm 0.018$, $P=0.002$ ) in the polymorphic subgroup (Table 2). Also regarding androgen parameters, these women with polymorphic genotype exhibited elevated free testosterone $(22.81 \pm 9.91$ vs $17.95 \pm 6.87 \mathrm{pmol} / \mathrm{l}, P=0.04)$, bioavailable testosterone $(0.54 \pm 0.23$ vs $0.42 \pm$ $0.16 \mathrm{nmol} / \mathrm{l}, P=0.04)$, and FAI $(2.94 \pm 1.50 \mathrm{vs}$ $2.16 \pm 0.82, P=0.02$; Table 2 ). The variables that 


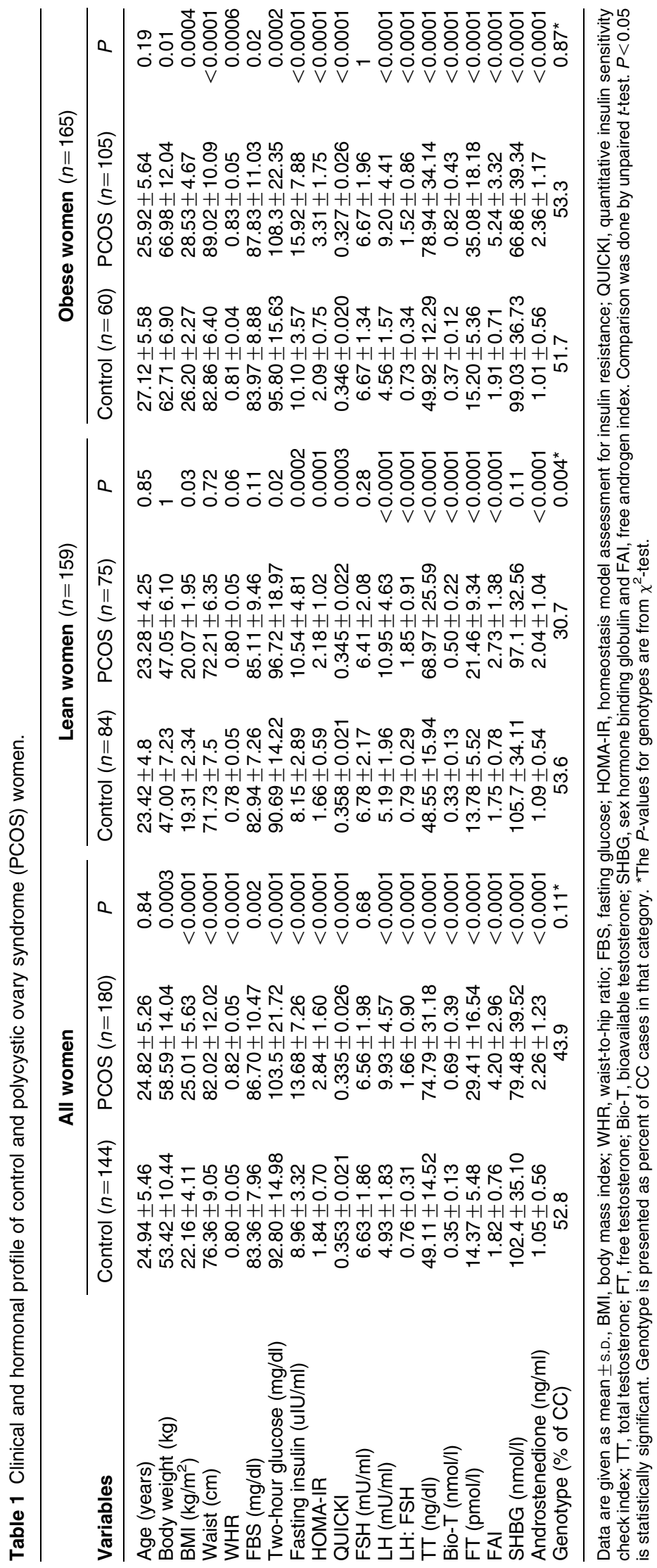


Table 2 Insulin resistance indices and hormonal profile of lean and obese women with polycystic ovary syndrome (PCOS) according to genotype.

\begin{tabular}{|c|c|c|c|c|c|c|c|}
\hline \multirow[b]{2}{*}{ Variables } & \multicolumn{4}{|c|}{ Lean PCOS $(n=75)$} & \multicolumn{3}{|c|}{ Obese PCOS $(n=105)$} \\
\hline & $\mathrm{CC}(n=23)$ & $\mathrm{CT}+\mathrm{TT}(n=52)$ & $P^{*}$ & $P^{\dagger}$ & $\mathrm{CC}(n=56)$ & $\mathrm{CT}+\mathrm{TT}(n=49)$ & $P^{*}$ \\
\hline Age (years) & $21.87 \pm 4.15$ & $23.90 \pm 4.18$ & 0.06 & & $25.63 \pm 5.50$ & $26.27 \pm 5.82$ & 0.56 \\
\hline Waist $(\mathrm{cm})$ & $69.89 \pm 5.64$ & $73.24 \pm 6.43$ & 0.03 & 0.43 & $88.60 \pm 9.90$ & $89.50 \pm 10.38$ & 0.65 \\
\hline BMI $\left(\mathrm{kg} / \mathrm{m}^{2}\right)$ & $19.15 \pm 2.07$ & $20.48 \pm 1.77$ & 0.005 & & $28.79 \pm 5.22$ & $28.23 \pm 3.97$ & 0.54 \\
\hline FBS (mg/dl) & $84.30 \pm 6.77$ & $85.26 \pm 10.47$ & 0.68 & & $87.22 \pm 11.47$ & $88.53 \pm 10.58$ & 0.54 \\
\hline Two-hour glucose (mg/dl) & $93.04 \pm 7.50$ & $98.36 \pm 19.34$ & 0.26 & & $107.0 \pm 20.04$ & $109.9 \pm 24.85$ & 0.51 \\
\hline Fasting insulin (ulU/ml) & $8.32 \pm 2.7$ & $11.43 \pm 5.22$ & 0.009 & 0.02 & $15.96 \pm 8.53$ & $15.87 \pm 7.15$ & 0.95 \\
\hline HOMA-IR & $1.64 \pm 0.54$ & $2.40 \pm 1.10$ & 0.002 & 0.005 & $3.20 \pm 1.73$ & $3.43 \pm 1.80$ & 0.52 \\
\hline QUICKI & $0.357 \pm 0.018$ & $0.340 \pm 0.021$ & 0.002 & 0.004 & $0.328 \pm 0.029$ & $0.325 \pm 0.023$ & 0.56 \\
\hline TT (ng/dl) & $64.96 \pm 26.36$ & $70.11 \pm 25.48$ & 0.43 & & $79.20 \pm 34.71$ & $78.65 \pm 33.83$ & 0.94 \\
\hline Bio-T (nmol/l) & $0.42 \pm 0.16$ & $0.54 \pm 0.23$ & 0.04 & 0.057 & $0.82 \pm 0.41$ & $0.83 \pm 0.45$ & 0.85 \\
\hline $\mathrm{FT}(\mathrm{pmol} / \mathrm{l})$ & $17.95 \pm 6.87$ & $22.81 \pm 9.91$ & 0.04 & 0.056 & $34.77 \pm 17.35$ & $35.44 \pm 19.27$ & 0.85 \\
\hline FAI & $2.16 \pm 0.82$ & $2.94 \pm 1.50$ & 0.02 & 0.03 & $5.16 \pm 3.06$ & $5.38 \pm 3.63$ & 0.73 \\
\hline SHBG $(\mathrm{nmol} / \mathrm{l})$ & $107.3 \pm 29.21$ & $92.42 \pm 32.94$ & 0.07 & & $68.52 \pm 40.59$ & $64.96 \pm 38.20$ & 0.65 \\
\hline Androstenedione $(\mathrm{ng} / \mathrm{ml})$ & $1.92 \pm 0.81$ & $2.07 \pm 1.14$ & 0.57 & & $2.33 \pm 1.13$ & $2.38 \pm 1.24$ & 0.80 \\
\hline
\end{tabular}

Data are given as mean \pm S.D. BMI, body mass index; FBS, fasting glucose; HOMA-IR, homeostasis model assessment for insulin resistance; QUICKI, quantitative insulin sensitivity check index; TT, total testosterone; FT, free testosterone, Bio-T, bioavailable testosterone; SHBG, sex hormone binding globulin and $\mathrm{FAI}$, free androgen index. ${ }^{*} P$-values are from unpaired $t$-test. The significant variables at the univariate level were further assessed in an ANCOVA model. ${ }^{\dagger} P$-values are from ANCOVA after adjusting for age and BMI. $P<0.05$ is statistically significant.

showed significant association with genotype in univariate analysis were further evaluated by ANCOVA model, in the lean PCOS group. In multivariate analysis after adjusting for age and BMI, the difference in fasting insulin $(P=0.02)$, HOMA-IR $(P=0.005)$, QUICKI $(P=0.004)$ and FAI $(P=0.03)$ between polymorphic and wildtype genotype remained significant, whereas free and bioavailable testosterone were marginally significant (Table 2).

\section{Discussion}

To the best of our knowledge, this is the first study from India, reporting the presence of the $\mathrm{C} / \mathrm{T}$ polymorphism at His1058 in exon 17 of INSR. The polymorphism showed a strong association with PCOS in lean women. Detailed analysis also revealed an association of this polymorphism with indices of insulin resistance (fasting insulin levels, HOMA-IR, and QUICKI) and hyperandrogenemia (FAI) in the same subgroup. It may be mentioned here that our study cohort is larger than the other published reports which examined exon 17 polymorphism of INSR in PCOS women.

It is well established that insulin resistance, PCOS, and obesity are interrelated $(36,37)$. Interestingly, stratifying the study cohort into lean and obese groups, the prevalence of polymorphic genotype was significantly higher in the lean PCOS group compared with lean control, obese PCOS as well as obese control groups. The analysis clearly establishes an association

Table 3 Insulin resistance indices and hormonal profile of lean and obese control women according to genotype.

\begin{tabular}{|c|c|c|c|c|c|c|}
\hline \multirow[b]{2}{*}{ Variables } & \multicolumn{3}{|c|}{ Lean control $(n=84)$} & \multicolumn{3}{|c|}{ Obese control $(n=60)$} \\
\hline & $\mathrm{CC}(n=45)$ & $\mathrm{CT}+\mathrm{TT}(n=39)$ & $P$ & $\mathrm{CC}(n=31)$ & $\mathrm{CT}+\mathrm{TT}(n=29)$ & $P$ \\
\hline Age (years) & $22.65 \pm 5.08$ & $23.93 \pm 4.61$ & 0.49 & $26.42 \pm 5.34$ & $27.70 \pm 5.78$ & 0.37 \\
\hline Waist (cm) & $71.33 \pm 8.06$ & $72.03 \pm 6.08$ & 0.67 & $83.18 \pm 5.41$ & $83.23 \pm 8.37$ & 0.98 \\
\hline BMI $\left(\mathrm{kg} / \mathrm{m}^{2}\right)$ & $19.45 \pm 2.33$ & $19.14 \pm 2.37$ & 0.54 & $26.37 \pm 2.27$ & $26.13 \pm 2.32$ & 0.69 \\
\hline FBS (mg/dl) & $82.43 \pm 7.99$ & $83.88 \pm 6.31$ & 0.36 & $84.00 \pm 9.22$ & $83.43 \pm 9.07$ & 0.80 \\
\hline Two-hour glucose (mg/dl) & $91.24 \pm 13.35$ & $89.45 \pm 15.45$ & 0.58 & $97.03 \pm 16.89$ & $95.37 \pm 14.51$ & 0.66 \\
\hline Fasting insulin (ulU/ml) & $8.00 \pm 2.62$ & $8.37 \pm 3.14$ & 0.55 & $9.98 \pm 3.61$ & $10.15 \pm 3.54$ & 0.85 \\
\hline HOMA-IR & $1.62 \pm 0.52$ & $1.73 \pm 0.66$ & 0.38 & $2.12 \pm 0.83$ & 2. $05 \pm 0.67$ & 0.73 \\
\hline QUICKI & $0.358 \pm 0.019$ & $0.357 \pm 0.021$ & 0.70 & $0.347 \pm 0.020$ & $0.346 \pm 0.018$ & 0.79 \\
\hline $\mathrm{TT}(\mathrm{ng} / \mathrm{dl})$ & $48.67 \pm 16.63$ & $48.38 \pm 15.18$ & 0.93 & $47.77 \pm 11.89$ & $51.93 \pm 12.14$ & 0.18 \\
\hline Bio-T (nmol/l) & $0.32 \pm 0.13$ & $0.37 \pm 0.13$ & 0.54 & $0.35 \pm 0.10$ & $0.39 \pm 0.13$ & 0.23 \\
\hline $\mathrm{FT}(\mathrm{pmol} / \mathrm{l})$ & 13. $21 \pm 5.50$ & $14.40 \pm 5.61$ & 0.32 & $14.06 \pm 4.85$ & $16.29 \pm 5.54$ & 0.10 \\
\hline FAl & $1.66 \pm 0.72$ & $1.85 \pm 0.84$ & 0.26 & $1.83 \pm 0.65$ & $1.99 \pm 0.76$ & 0.37 \\
\hline SHBG $(\mathrm{nmol} / \mathrm{l})$ & $110.0 \pm 34.70$ & $101.5 \pm 33.43$ & 0.25 & $98.87 \pm 39.47$ & $98.93 \pm 28.34$ & 1.0 \\
\hline Androstenedione $(\mathrm{ng} / \mathrm{ml})$ & $1.12 \pm 0.60$ & $1.05 \pm 0.53$ & 0.60 & $0.96 \pm 0.52$ & $1.05 \pm 0.60$ & 0.55 \\
\hline
\end{tabular}

Data are given as mean +s.D. BMI, body mass index; FBS, fasting glucose; HOMA-IR, homeostasis model assessment for insulin resistance; QUICKI, quantitative insulin sensitivity check index; TT, total testosterone; FT, free testosterone, Bio-T, bioavailable testosterone; SHBG, sex hormone binding globulin; $\mathrm{FAI}$, free androgen index. Comparison was done by unpaired $t$-test. $P<0.05$ is statistically significant. 
of the polymorphic allele with PCOS in lean women, thus corroborating the previous findings in Caucasian and Chinese women $(25,26)$. A significantly higher frequency of CT + TT genotype was reported in lean Caucasian PCOS women compared with lean controls (47 vs $29 \%, P=0.03$ ) (25). Similarly, prevalence of polymorphic allele was more in non-obese Chinese PCOS women compared with obese PCOS women $(52.2$ vs $25.5 \%, P<0.01$ ) (26). In our study, the frequency of polymorphic genotype in lean PCOS (69.3\%) was higher than the frequencies reported earlier, which may be attributed to ethnic variation. A similar Korean study had not found any such association (27).

It is known that insulin resistance is present in PCOS women irrespective of obesity $(38,39$, Mukherjee unpublished observations). However, in the present study, an association of this polymorphism in INSR with PCOS only in lean women was observed. This prompted us to investigate the relationship of His1058 genotypes with PCOS associated traits. Univariate analysis revealed the association of polymorphic genotype with BMI, waist circumference, fasting insulin levels, HOMAIR, and QUICKI, only in lean PCOS group. It is interesting that lean PCOS women with polymorphic genotype had significantly higher waist circumference, which is a measure of central obesity compared with wildtype genotype. It has now been reported that the central obesity is more in Asian Indians, causing higher insulin resistance despite having lean BMI (34). Indeed, the same subgroup of PCOS women also had higher indices of insulin resistance. Hyperinsulinemia is known to exacerbate PCOS phenotypes by inducing hyperandrogenemia, through excess ovarian androgen production and suppressing hepatic SHBG synthesis (2, 40). In keeping with this evidence, the lean PCOS subgroup with polymorphic genotype also showed increased free bioavailable testosterone and FAI. Even with adjustments for age and BMI in multivariate analysis, this association persisted with respect to indices of insulin resistance and hyperandrogenemia in lean PCOS. These associations suggest that the pathogenesis of insulin resistance in PCOS may differ among lean and obese women. Dunaif et al. also observed that insulin resistance in $50 \%$ of PCOS women is associated with decreased tyrosine autophosphorylation and increased serine phosphophorylation of INSR (2). Indeed, this emphasizes that molecular mechanism of insulin resistance may differ in different PCOS group. Improvement of hyperinsulinemia and hyperandrogenemia in PCOS women by treatment with insulin sensitizer metformin occurs through different mechanisms in obese and lean women (41), which again supports the notion that the pathogenic mechanism is different in these two groups. A recent study reported the presence of three subpopulations with distinct levels of insulin resistance in PCOS women with significantly different BMI (39). With our present data, it is not possible to identify such subpopulations.
However, the association of His1058 SNP with lean PCOS emphasizes that the genetic determinants of these subpopulations might be different.

Beyond His1058, few other polymorphisms also have been reported in exon 17 of INSR in women with PCOS $(21,23,28)$. A novel T/C polymorphism at Cys1008 has been reported to be associated with PCOS and decreased insulin sensitivity in Chinese population (28). Studies reported another silent $\mathrm{C} / \mathrm{T}$ variation in Tyr984 in PCOS women as well as in diabetic subjects $(21,23$, 42). However, none of these polymorphisms or other novel variation in exon 17 of INSR was found in this study cohort.

PCOS is now considered as a complex multigenic trait, where different gene variants interact with each other and also with environmental factors in the manifestation of different phenotypic expressions of the syndrome. It is possible that different subgroups of PCOS with specific phenotypic expression are associated with specific gene variants. Since the $\mathrm{C} / \mathrm{T}$ SNP at His 1058 is a silent one, it cannot exert a major effect on the development of insulin resistance; rather it might be in linkage disequilibrium with some other genetic variants, which may play a direct role in the development of PCOS by affecting insulin sensitivity in lean women. This polymorphism may predispose lean women to develop insulin resistance and compensatory hyperinsulinemia, which then may induce hyperandrogenemia progressing towards PCOS. The lower prevalence of the $\mathrm{T}$ allele in obese compared with lean women could also suggest that this allele either has a protective role against obesity in lean women or may reduce the risk of developing PCOS in obese women.

To summarize, this study in Indian women shows an association of the C/T polymorphism at His1058 of INSR with PCOS in lean rather than obese women. The polymorphism is also seen to be associated with the indices of insulin resistance and hyperandrogenemia in the lean PCOS group. The observations made herein strongly suggest that the genetic pathogenic mechanism of this heterogeneous disorder may differ between lean and obese PCOS, which needs to be studied further.

\section{Declaration of interest}

The authors declare that there is no conflict of interest that could be perceived as prejudicing the impartiality of the research reported.

\section{Funding}

This work was supported by a grant from Department of Science and Technology, India (SR/SO/HS-60/2005).

\section{Acknowledgements}

We thank Dr Mousumi Banerjee, Department of Biostatistics, University of Michigan, and Ann Arbor, Michigan, USA for her help in statistical analysis. We acknowledge Dr Padma Menon and the 
Endocrine Department of Seth GS Medical College and KEM Hospital, Mumbai, India for their contributions. We also thank Mr Chinnaraj Saravanan (DNA sequencing core facility, NIRRH) for his help in DNA sequencing.

\section{References}

1 Diamanti-Kandarakis E. Polycystic ovarian syndrome: pathophysiology, molecular aspects and clinical implications. Expert Reviews in Molecular Medicine 200810 e3.

2 Dunaif A. Insulin resistance and the polycystic ovary syndrome: mechanism and implications for pathogenesis. Endocrine Reviews $199718774-800$.

3 Franks S. Polycystic ovary syndrome. New England Journal of Medicine 1995333 853-861.

4 Azziz R, Woods KS, Reyna R, Key TJ, Knochenhauer ES \& Yildiz BO. The prevalence and features of polycystic ovary syndrome in an unselected population. Journal of Clinical Endocrinology and Metabolism 200489 2754-2759.

5 Legro RS, Kunselman AR, Dodson WC \& Dunaif A. Prevalence and predictors for risk for type 2 diabetes mellitus and impaired glucose tolerance in polycystic ovary syndrome: a prospective, controlled study in 254 affected women. Journal of Clinical Endocrinology and Metabolism 199984 165-169.

6 Diamanti-Kandarakis E. Insulin resistance in PCOS. Endocrine 200630 13-17.

7 Legro RS, Finegood D \& Dunaif A. Changes in glucose tolerance over time in women with polycystic ovary syndrome: a controlled study. Journal of Clinical Endocrinology and Metabolism 200590 3236-3242.

8 Wild RA, Grubb B, Hartz A, Van Nort JJ, Bachman W \& Bartholomew M. Clinical signs of androgen excess as risk factors for coronary artery disease. Fertility and Sterility $1990 \mathbf{5 4}$ $255-259$.

9 Maitra A, Meherji PK, Desai MP, Gokral JS, Donde UM \& Joshi UM. Lipoprotein in androgen excess - a study among Indian women. International Journal of Fertility 199439 218-222.

10 Maitra A, Pingle RR, Menon PS, Naik V, Gokral JS \& Meherji PK. Dyslipidemia with particular regard to apolipoprotein profile in association with polycystic ovary syndrome: a study among Indian women. International Journal of Fertility and Women's Medicine 200146 271-277.

11 Bjornthorp P. Hyperandrogenicity in women - a prediabetic condition? Journal of Internal Medicine 1993234 609-613.

12 Lunde O, Magnus P, Sandvik L \& Høglo S. Familial clustering in the polycystic ovarian syndrome. Gynecologic and Obstetric Investigation 198928 23-30.

13 Yildiz BO, Yarali H, Oguz H \& Bayraktar M. Glucose intolerance, insulin resistance, and hyperandrogenemia in first degree relatives of women with polycystic ovary syndrome. Journal of Clinical Endocrinology and Metabolism $2003 \mathbf{8 8}$ 2031-2036.

14 Escobar-Morreale HF, Luque-Ramírez M \& San Millán JL. The molecular-genetic basis of functional hyperandrogenism and the polycystic ovary syndrome. Endocrine Reviews 200526 251-282.

15 Diamanti-Kandarakis E, Piperi C, Spina J, Argyrakopoulou G, Papanastasiou L, Bergiele A \& Panidis D. Polycystic ovary syndrome: the influence of environmental and genetic factors. Hormones 20065 17-34.

16 Dunaif A, Xia J, Book CB, Schenker E \& Tang Z. Excessive insulin receptor serine phosphorylation in cultured fibroblasts and in skeletal muscle, A potential mechanism for insulin resistance in the polycystic ovary syndrome. Journal of Clinical Investigation $199596801-810$.

17 Diamanti-Kandarakis E \& Papavassiliou AG. Molecular mechanisms of insulin resistance in polycystic ovary syndrome. Trends in Molecular Medicine 200612 324-332.
18 Urbanek M, Legro RS, Driscoll DA, Azziz R, Ehrmann DA, Norman RJ, Strauss JF 3rd, Spielman RS \& Dunaif A. Thirty-seven candidate genes for polycystic ovary syndrome: strongest evidence for linkage is with follistatin. PNAS $1999968573-8578$.

19 Tucci S, Futterweit W, Concepcion ES, Greenberg DA, Villanueva R, Davies TF \& Tomer Y. Evidence for association of polycystic ovary syndrome in caucasian women with a marker at the insulin receptor gene locus. Journal of Clinical Endocrinology and Metabolism 200186 446-449.

20 Ciaraldi TP, el-Roeiy A, Madar Z, Reichart D, Olefsky JM \& Yen SS. Cellular mechanisms of insulin resistance in polycystic ovarian syndrome. Journal of Clinical Endocrinology and Metabolism 1992 75 577-583.

21 Talbot J, Bicknell E, Rajkhowa M, Krook A, O’Rahilly S \& Clayton RN. Molecular scanning of the insulin receptor gene in women with polycystic ovarian syndrome. Journal of Clinical Endocrinology and Metabolism 199681 1979-1983.

22 Krook A, Kumar S, Laing I, Boulton AJ, Wass JA \& O'Rahilly S. Molecular scanning of the insulin receptor gene in syndromes of insulin resistance. Diabetes 199443 357-368.

23 Moller DE, Cohen O, Yamaguchi Y, Azziz R, Grigorescu F, Eberle A, Morrow LA, Moses AC \& Flier JS. Prevalence of mutations in the insulin receptor gene in subjects with features of the type A syndrome of insulin resistance. Diabetes 199443 247-255.

24 Panz VR, Ruff P, Joffe BI, Kedda MA \& Seftel HC. SSCP analysis of the tyrosine kinase domain of the insulin receptor gene: polymorphisms detected in South African black and white subjects. Human Genetics 19967 438-440.

25 Siegel S, Futterweit W, Davies TF, Concepcion ES, Greenberg DA, Villanueva R \& Tomer Y. A C/T single nucleotide polymorphism at the tyrosine kinase domain of the insulin receptor gene is associated with PCOS. Fertility and Sterility $2002 \mathbf{7 8}$ 1240-1243.

26 Chen ZJ, Shi YH, Zhao YR, Li Y, Tang R, Zhao LX \& Chang ZH. Correlation between single nucleotide polymorphism of insulin receptor gene with polycystic ovary syndrome. Zhonghua $\mathrm{Fu}$ Chan Ke Za Zhi 200439 582-585.

27 Lee EJ, Yoo KJ, Kim SJ, Lee SH, Cha KY \& Baek KH. Single nucleotide polymorphism in exon 17 of the insulin receptor gene is not associated with polycystic ovary syndrome in a Korean population. Fertility and Sterility $2006 \mathbf{8 6} 380-384$.

28 Jin L, Zhu XM, Luo Q, Qian Y, Jin F \& Huang HF. A novel SNP at exon 17 of INSR is associated with decreased insulin sensitivity in Chinese women with PCOS. Molecular Human Reproduction 2006 12 151-155.

29 The Rotterdam ESHRE/ASRM-sponsored PCOS consensus workshop group. Revised 2003 consensus on diagnostic criteria and long-term health risks related to polycystic ovary syndrome (PCOS). Human Reproduction 200419 41-47.

30 Vermeulen A, Verdonck L \& Kaufman JM. A critical evaluation of simple methods for the estimation of free testosterone in serum. Journal of Clinical Endocrinology and Metabolism $1999 \mathbf{8 4}$ 3666-3672.

31 Clark AF, Marcellus S, deLory B \& Bird CE. Plasma testosterone free index: a better indicator of plasma androgen activity? Fertility and Sterility 197526 1001-1005.

32 Matthews DR, Hosker JP, Rudenski AS, Naylor BA, Treacher DF \& Turner RC. Homeostasis model assessment: insulin resistance and beta-cell function from fasting plasma glucose and insulin concentrations in man. Diabetologia 198528 412-419.

33 Katz A, Nambi SS, Mather K, Baron AD, Follmann DA, Sullivan G \& Quon MJ. Quantitative insulin sensitivity check index: a simple, accurate method for assessing insulin sensitivity in humans. Journal of Clinical Endocrinology and Metabolism $2000 \mathbf{8 5}$ 2402-2410.

34 Snehalatha C, Viswanathan V \& Ramachandran A. Cutoff values for normal anthropometric variables in Asian Indian adults. Diabetes Care 200326 1380-1384.

35 Sikaris KA. The clinical biochemistry of obesity more than skin deep. Heart, Lung and Circulation 200716 S45-S50. 
36 Allahbadia GN \& Merchant R. Polycystic ovary syndrome in the Indian subcontinent. Seminars in Reproductive Medicine 200826 $22-34$.

37 Gambineri A, Pelusi C, Vicennati V, Pagotto U \& Pasquali R. Obesity and the polycystic ovary syndrome. International Journal of Obesity and Related Metabolic Disorders 200226 883-896.

38 Dunaif A, Segal KR, Futterweit W \& Dobrjansky A. Profound peripheral insulin resistance, independent of obesity, in polycystic ovary syndrome. Diabetes $1989 \mathbf{3 8} 1165-1174$.

39 Vigil P, Contreras P, Alvarado JL, Godoy A, Salgado AM \& Cortés ME. Evidence of subpopulations with different levels of insulin resistance in women with polycystic ovary syndrome. Human Reproduction $2007112974-2980$.

40 Tsilchorozidou T, Overton C \& Conway GS. The pathophysiology of polycystic ovary syndrome. Clinical Endocrinology 200460 1-17.
41 Morin-Papunen L, Vauhkonen I, Koivunen R, Ruokonen A, Martikainen H \& Tapanainen JS. Metformin versus ethinyl estradiol-cyproterone acetate in the treatment of nonobese women with polycystic ovary syndrome: a randomized study. Journal of Clinical Endocrinology and Metabolism $2003 \mathbf{8 8}$ $148-156$.

42 Elbein SC \& Sorensen LK. Genetic variation in insulin receptor beta-chain exons among members of familial type 2 (noninsulin-dependent) diabetic pedigrees. Diabetologia 199134 $742-749$.

Received 20 January 2009

Accepted 7 February 2009 